\title{
Prebiotic fibres dose-dependently increase satiety hormones and alter Bacteroidetes and Firmicutes in lean and obese JCR:LA-cp rats
}

\author{
Jill A. Parnell ${ }^{1}$ and Raylene A. Reimer ${ }^{2 *}$ \\ ${ }^{1}$ Department of Physical Education and Recreation Studies, Mount Royal University, 4825 Mount Royal Gate SW, Calgary, \\ AB, Canada T3E 6 K6 \\ ${ }^{2}$ Faculties of Kinesiology and Medicine, Department of Biochemistry and Molecular Biology, University of Calgary, 2500 \\ University Drive NW, Calgary AB, Canada T2N $1 N 4$
}

(Received 10 January 2011 - Revised 5 May 2011 - Accepted 9 May 2011 - First published online 15 July 2011)

\section{Abstract}

There is a growing interest in modulating gut microbiota with diet in the context of obesity. The purpose of the present study was to evaluate the dose-dependent effects of prebiotics (inulin and oligofructose) on gut satiety hormones, energy expenditure, gastric emptying and gut microbiota. Male lean and obese JCR:LA-cp rats were randomised to either of the following: lean $0 \%$ fibre (LC), lean $10 \%$ fibre (LF), lean $20 \%$ fibre (LHF), obese $0 \%$ fibre (OC), obese $10 \%$ fibre (OF) or obese $20 \%$ fibre (OHF). Body composition, gastric emptying, energy expenditure, plasma satiety hormone concentrations and gut microbiota (using quantitative PCR) were measured. Caecal proglucagon and peptide YY mRNA levels were up-regulated 2-fold in the LF, OF and OHF groups and 3-fold in the LHF group. Ghrelin O-acyltransferase mRNA levels were higher in obese $v$. lean rats and decreased in the OHF group. Plasma ghrelin response was attenuated in the LHF group. Microbial species measured in the Bacteroidetes division decreased, whereas those in the Firmicutes increased in obese $v$. lean rats and improved with prebiotic intake. Bifidobacterium and Lactobacillus increased in the OHF $v$. OC group. Bacteroides and total bacteria negatively correlated with percentage of body fat and body weight. Enterobacteriaceae increased in conjunction with glucose area under the curve (AUC) and glucagon-like peptide-1 AUC. Bacteroides and total bacteria correlated positively with ghrelin AUC yet negatively with insulin AUC and energy intake $(P<0.05)$. Several of the mechanisms through which prebiotics act (food intake, satiety hormones and alterations in gut microbiota) are regulated in a dose-dependent manner. The combined effects of prebiotics may have therapeutic potential for obesity.

Key words: Inulin: Oligofructose: Satiety response: Gut microbiota

Prebiotic fibres represent oligosaccharides that are resistant to human digestive enzymes but can be fermented by bacteria in the caeco-colon ${ }^{(1)}$. Several studies have demonstrated that supplementing the diet, both standard chow ${ }^{(2)}$ and high fat $^{(3,4)}$, of rodents with inulin, oligofructose or a combination of the two reduces energy intake and fat mass. Suggestions as to the mechanisms responsible for these effects have included alterations in satiety hormone secretion, delayed gastric emptying, energy dilution, increased energy expenditure and modulation of gut microflora.

The intestinal mucosa, primarily in the distal ileum, caecum and colon, contains endocrine L-cells that secrete peptides in response to nutrient stimulus ${ }^{(5-7)}$. Of particular interest, with respect to weight loss, are the two L-cell-derived anorexigenic peptides, glucagon-like peptide-1 (GLP-1) and peptide
YY (PYY), and the X/A-like cell-derived orexigenic peptide ghrelin. Prebiotics have been shown to increase GLP-1 and PYY in human subjects ${ }^{(8,9)}$ and rodent models ${ }^{(2,3,10-12)}$. Expression of proglucagon, the precursor of GLP-1, can be up-regulated by SCFA, the end products of fibre fermentation in the gut ${ }^{(12,13)}$. Ghrelin, which is acylated via the actions of ghrelin $O$-acyltransferase $(\mathrm{GOAT})^{(14,15)}$, has also been shown to decrease in response to prebiotic supplementation in rats ${ }^{(2,3)}$ and human subjects ${ }^{(8)}$.

Given that oligofructose-enriched diets stimulate the secretion of GLP-1, which in turn inhibits gastric motility via its actions as an ileal break ${ }^{(16)}$, it is plausible that prebiotic fibre may delay gastric emptying, although this suggestion lacks confirmation in an obese model. Furthermore, inulintype fructans contain only $6.3 \mathrm{~kJ} / \mathrm{g}$ as opposed to digestible

Abbreviations: C, control; F, fibre; GLP-1, glucagon-like peptide-1; GOAT, ghrelin $O$-acyltransferase; HF, high fibre; iAUC, incremental area under the curve; LC, lean $0 \%$ fibre; LF, lean $10 \%$ fibre; LHF, lean $20 \%$ fibre; OC, obese $0 \%$ fibre; OF, obese $10 \%$ fibre; OHF, obese $20 \%$ fibre; PYY, peptide YY; tAUC, total area under the curve.

*Corresponding author: Dr R. A. Reimer, fax +1 403284 3553, email reimer@ucalgary.ca 
carbohydrates, which have an energy value of $16.7 \mathrm{~kJ} / \mathrm{g}^{(17)}$. As a result, supplementation with these fibres lowers the energy content of the diet. In general, rats will compensate for the lower energy content of a fibre-enriched diet with hyperphagia ${ }^{(18)}$; however, diets enriched in inulin-type fructans appear to be an exception ${ }^{(12)}$. Whether the weight loss associated with prebiotic supplementation is due to increased satiety, energy dilution or a combination of the two remains controversial.

The human gut is colonised by large numbers of bacteria that utilise dietary substances that would otherwise be non-digestible ${ }^{(19)}$. Recently, obesity has been linked to dysbiosis of the gut microbiota ${ }^{(20)}$. Furthermore, the gut microbiota has also been shown to play a role in metabolic endotoxaemia, the low-grade inflammatory tone linked to obesity and many of its co-morbidities ${ }^{(21,22)}$. Generally, obesity is associated with a reduction in Bacteroidetes and an increase in Firmicutes ${ }^{(23)}$; nevertheless, this remains controversial ${ }^{(24,25)}$. It has been proposed that changes at the smaller microbial community level rather than at the phylum level are involved in the development of obesity ${ }^{(20)}$; however, this requires further investigation as does the potential for prebiotic fibres to modulate the gut microbiota to promote weight loss. A recent study has suggested that gut bifidobacteria are lower in obesity and with high-fat feeding and that supplementing the diet of mice with prebiotics restores bifidobacteria numbers and reduces metabolic endotoxaemia caused by a high-fat diet ${ }^{(26)}$. The effects of prebiotic fibres on other bacterial population in obesity remain understudied. Finally, metabolic rate is decreased in germ-free mice compared with conventionalised mice, suggesting that the microbial community may affect energy expenditure ${ }^{(27)}$.

The purpose of the present study was to examine the dosedependent effects of prebiotic fibre on body-weight regulation in lean and obese littermates of the genetically obese JCR:LA-cp rat strain. Primary outcome measures following
10 weeks of inulin and oligofructose consumption included plasma satiety hormones, gastric emptying, energy expenditure and gut microbiota.

\section{Methods}

\section{Animal model}

Male lean $(+/$ ?; which includes $c p /+$ and $+/+)$ and obese $(c p / c p)$ JCR:LA-cp rats (8 weeks of age) were obtained from the colony of Dr Spencer Proctor (University of Alberta, Edmonton, AB, Canada). Due to the lack of a functional leptin receptor, they are severely obese and exhibit marked hyperphagia and hyperinsulinaemia in combination with altered intestinal physiology ${ }^{(28,29)}$. All procedures were approved by the University of Calgary Animal Care Committee and conformed to the procedures set forth for the Care and Use of Laboratory Animals.

\section{Dietary intervention}

At 8 weeks of age, the animals were randomly assigned to ad libitum control (C) $0 \%$, fibre (F) $10 \%$ or high-fibre (HF) $20 \%$ inulin:oligofructose $(\mathrm{w} / \mathrm{w})$ diets (Table 1$)$ for 10 weeks (eight animals per group). The composition of the diets and the energy contribution of the composite macronutrients are shown in Table 1. Food intake was recorded daily.

\section{Gastric emptying}

Measurements of gastric emptying were performed in lean and obese rats from each diet group $(n 6)$ in week 6 using the acetaminophen $\operatorname{method}^{(30)}$. Following an overnight fast, acetaminophen $(100 \mathrm{mg} / \mathrm{kg}$ ) was added to $2 \mathrm{~g}$ of each group's respective diet and dissolved in distilled water at a $50 \%$ concentration. A fasting blood sample was taken followed by administration of the mixture by oral administration.

Table 1. Composition of the experimental diets ${ }^{*}$

\begin{tabular}{|c|c|c|c|}
\hline & Control & $10 \%$ Prebiotic fibre & $20 \%$ Prebiotic fibre \\
\hline \multicolumn{4}{|l|}{$\mathrm{g} / \mathrm{kg}$} \\
\hline Maize starch & $46 \cdot 69$ & 39.45 & 33.51 \\
\hline Casein & 14.04 & $13 \cdot 11$ & $12 \cdot 03$ \\
\hline Dextrinised maize starch & $15 \cdot 54$ & 14.51 & $13 \cdot 32$ \\
\hline Sucrose & $10 \cdot 03$ & $9 \cdot 36$ & 8.59 \\
\hline Soyabean oil & 4.01 & 3.75 & 3.44 \\
\hline AIN-93M-MX & 3.51 & 3.48 & 3.39 \\
\hline AIN-93-VX & 1.00 & 0.99 & 0.96 \\
\hline Choline bitartrate & 0.18 & 0.18 & $0 \cdot 17$ \\
\hline L-Cys & 0.25 & 0.25 & 0.24 \\
\hline Alphacel & 5.01 & 4.97 & 4.83 \\
\hline Prebiotic fibre† & 0.00 & 9.94 & $19 \cdot 53$ \\
\hline Digestible energy $(\mathrm{kJ} / \mathrm{g}) \ddagger$ & $15 \cdot 90$ & $14 \cdot 81$ & $13 \cdot 81$ \\
\hline Carbohydrate (\% total energy) & $75 \cdot 8$ & 71.5 & $66 \cdot 8$ \\
\hline Protein (\% total energy) & 14.7 & $14 \cdot 7$ & $14 \cdot 7$ \\
\hline Fat (\% total energy) & 9.5 & 9.5 & 9.5 \\
\hline Prebiotic fibre (\% total energy) & 0 & $4 \cdot 2$ & $9 \cdot 0$ \\
\hline
\end{tabular}

* Based on the AIN-93 (Dyets, Inc., Bethlehem, PA, USA) diet for the maintenance of adult rats.

$\dagger$ 1:1 ratio of inulin:oligofructose supplied as Orafi Rafiline HP (Quadra Chemicals Limited, Burlington, ON, Canada) and Orafti Raftilose (Quadra Chemicals Limited).

‡ Digestible energy includes energy provided by carbohydrates, protein, fats and prebiotic fibre. For prebiotic fibre, a value of $6.3 \mathrm{~kJ} / \mathrm{g}$ was used ${ }^{(17)}$. 
Additional blood samples were taken at times 15, 30, 60 and 90 min post-oral administration and assayed for acetaminophen concentrations by Calgary Laboratory Services (Calgary, $\mathrm{AB}$, Canada).

\section{Metabolic measurements}

Measurements of energy expenditure were made 1 week before killing. Following an overnight fast, animals were placed in specially designed plastic cages and allowed free access to their respective diets throughout the test. Respiratory gas measurements were made over a $23 \mathrm{~h}$ period in which the air was drawn from the cages, dried and sent to an Oxymax Analyzing System (Columbus Instruments, Columbus, $\mathrm{OH}$, USA) for $\mathrm{O}_{2}$ and $\mathrm{CO}_{2}$ analysis. To estimate the relative amount of carbohydrate and fat energy expenditure, the RER was calculated as the quotient of $\mathrm{VCO}_{2} / \mathrm{VO}_{2}$.

\section{Body composition}

Body weight was recorded weekly. On the day before killing, rats were lightly anaesthetised and a dual-energy X-ray absorptiometry scan was performed. Hologic QDR software for small animals was used to determine lean and fat mass (QDR 4500; Hologic, Inc., Bedford, MA, USA).

\section{Meal tolerance test}

Following an overnight fast, rats were anaesthetised (isoflurane) and a fasting blood sample drawn via cardiac puncture. Rats were allowed to awaken and then given an oral administration of $5 \mathrm{~g}$ of their respective diet dissolved in distilled water at $50 \%$ concentration. Additional blood samples were taken at 15, 30, 60 and 90 min post-oral administration. Approximately, $0.5 \mathrm{ml}$ of blood were collected from each rat into a chilled EDTA tube containing aprotinin (500 kallikrein inhibitor units/ml of blood; Sigma Chemical Company, Oakville, ON, Canada $)$ and diprotin A $(0.034 \mathrm{mg} / \mathrm{ml}$ of blood; MP Biomedical,
Solon, OH, USA). After the final draw, animals were killed by over anaesthetisation of gaseous isoflurane and tissues were collected.

\section{Gut characteristics}

The stomach, small intestine, caecum and colon were analysed for weight and length (when appropriate). The small intestine was divided into three equal parts and a portion from the distal end of each was snap-frozen in liquid $\mathrm{N}_{2}$. Samples from the fundus of the stomach, the caecum and proximal colon were also frozen and all samples were stored at $-80^{\circ} \mathrm{C}$.

\section{Plasma analysis}

Blood glucose concentrations were determined immediately at each time point using a 'One Touch' blood glucose meter (LifeScan Canada Limited, Burnaby, BC, Canada). Rat Endocrine LINCOplex kits were used to quantify GLP-1 (active), glucagon, amylin and insulin (Linco Research, Inc., Millipore, Billerica, MA, USA). The sensitivity of the multiplex kit is $55.6 \mathrm{pm}$ for insulin and $6.2 \mathrm{pm}$ for all other analytes. ELISA kits with a sensitivity of $12.5 \mathrm{fmol} / \mathrm{ml}$ were used to determine des-acyl ghrelin levels (Millipore, Billerica, MA, USA). Incremental area under the curve (iAUC) and total area under the curve (tAUC) were calculated ${ }^{(31)}$.

\section{RNA isolation and real-time $P C R$}

RNA isolation and real-time PCR were performed as described previously $^{(29)}$. Ghrelin, proglucagon and PYY mRNA were measured throughout the gastrointestinal tract. Additionally, ghrelin and GOAT were measured in the fundus of the stomach using previously published primer sequences ${ }^{(32)}$ Within each genetic group (lean and obese), the control diet was used as the control condition. For comparisons between genetic groups, the lean group was used as the control.

Table 2. Groups of micro-organisms, primers and bacteria genomic DNA standards for quantitative PCR

\begin{tabular}{|c|c|c|c|}
\hline Groups & Primers ( $\mathrm{F}$ and $\mathrm{R}$ ) & Genomic DNA & References \\
\hline Total bacteria & $\begin{array}{l}\text { F: ACTCCTACGGGAGGCAG } \\
\text { R: GTATTACCGCGGCTGCTG }\end{array}$ & Escherichia coli & $\begin{array}{l}\text { Amann et al. }{ }^{(60)} \\
\text { Liu et al. }\end{array}$ \\
\hline \multicolumn{4}{|l|}{ Firmicutes } \\
\hline Clostridium leptum (group IV)* & $\begin{array}{l}\text { F: GCACAAGCAGTGGAGT } \\
\text { R: CTTCCTCCGTTTGTCAA }\end{array}$ & Clostridium leptum & Matsuki et al. ${ }^{(62)}$ \\
\hline Clostridium coccoides (group XIV) & $\begin{array}{l}\text { F: ACTCCTACGGGAGGCAGC } \\
\text { R: GCTTCTTAGTCARGTACCG }\end{array}$ & Ruminococcus productus & $\begin{array}{l}\text { Amann et al. }{ }^{(60)} \\
\text { Franks et al. }\end{array}$ \\
\hline Lactobacillus spp. & $\begin{array}{l}\text { F: GAGGCAGCAGTAGGGAATCTTC } \\
\text { R: GGCCAGTTACTACCTCTATCCTTCTTC }\end{array}$ & Lactobacillus jensenii & Delroisee et al. ${ }^{(64)}$ \\
\hline \multicolumn{4}{|l|}{ Bacteriodetes } \\
\hline Bacteroides/Prevotella & $\begin{array}{l}\text { F: TCCTACGGGAGGCAGCAGT } \\
\text { R: CAATCGGAGTTCTTCGTG }\end{array}$ & Bacteroides thetaiotaomicron & $\begin{array}{l}\text { Bernhard \& Field(65) } \\
\text { Nadkarni et al. }^{(66)}\end{array}$ \\
\hline \multicolumn{4}{|l|}{ Actinobacteria } \\
\hline Bifidobacterium spp. & $\begin{array}{l}\text { F: CGCGTCYGGTGTGAAAG } \\
\text { R: CCCCACATCCAGCATCCA }\end{array}$ & Bifidobacterium adolescentis & Delroisee et al. ${ }^{(64)}$ \\
\hline \multicolumn{4}{|l|}{ Proteobacteria } \\
\hline Enterobacteriaceae & $\begin{array}{l}\text { F: CATTGACGTTACCCGCAGAAGAAGC } \\
\text { R: CTCTACGAGACTCAAGCTTGC }\end{array}$ & Escherichia coli & Bartosch et al. ${ }^{(67)}$ \\
\hline
\end{tabular}

F, forward; R, reverse.

* The primer set for $C$. leptum covers close relatives of $C$. leptum and does not cover the genus Rumminicocus. 
Fold change from control was calculated using the comparative cycle threshold method ${ }^{(33)}$.

\section{Microbial profiling using quantitative $P C R$}

Total bacterial DNA was extracted from approximately $200 \mathrm{mg}$ of caecal samples using the QIAamp DNA Stool Mini Kit. According to the manufacturer, DNA yield is typically $15-60 \mu \mathrm{g}$ and DNA concentration is typically $75-300 \mathrm{ng} / \mu \mathrm{l}$ (Qiagen, Mississauga, ON, Canada). Validation of the stool extraction kit was performed by spiking the stool samples with known amounts of gram + exogenous bacteria in two separate extraction experiments and measuring the colony-forming units by quantitative PCR. Recovery was \pm 100 colony-forming units. This procedure was used to confirm that the extraction was consistent and able to lyse the more difficult gram + bacteria. DNA concentrations were determined using the PicoGreen DNA quantification kit (Invitrogen, Carlsbad, CA, USA). Bacterial groups were quantified by quantitative PCR using the BioRad iCycler (BioRad, Inc., Mississauga, ON, Canada) and the group-specific primers are shown in Table 2. Normal PCR was run on all primer sets to determine optimal conditions. Additionally, group-specific primers were run against all negative control bacteria. Amplification efficiency and the limit of detection were determined using serial dilutions of the standards. Primer sets were confirmed to be within $2 \mathrm{bp}$ of known rat microbiota sequences by blasting primers against the 16S Ribosomal Database Project (http://rdp.cme.msu.edu/ hierarchy/hb_intro.jsp;jsessionid= 568E9C48ED3A5164E1E1D 69FEFC4C13C?timeout=true). The PCR was heated for $2 \mathrm{~min}$ at $95^{\circ} \mathrm{C}$, followed by forty-two cycles of $95^{\circ} \mathrm{C}$ for $20 \mathrm{~s}, 55^{\circ} \mathrm{C}$ for $30 \mathrm{~s}$ and $72^{\circ} \mathrm{C}$ for $30 \mathrm{~s}$ and a final cycle of $72^{\circ} \mathrm{C}$ for $2 \mathrm{~min}$. A melt curve analysis was run starting at $60^{\circ} \mathrm{C}$ and increased by $1^{\circ} \mathrm{C}$ every $8 \mathrm{~s}$. Real-time PCR assays were run in duplicate and standard curves constructed for each experiment using 10-fold serial dilutions of standard bacterial genomic DNA of known concentration (American Type Culture Collection, Manassas, VA, USA) specific for each primer. Cell numbers of bacteria in faecal samples were calculated from threshold cycle values and are expressed as mean pg bacterial DNA/ng total genomic DNA.

\section{Statistical analysis}

All data are presented as means and standard errors. Differences in body composition, gut characteristics, gut microbiota, food and energy intake and area under the curve were determined using two-factor ANOVA (with diet and genetic group (lean $v$. obese) as variables). Changes in gene expression between the diets within the lean and obese groups were analysed using one-way ANOVA and Tukey's post hoc test. Parameters with serial measurements were analysed with a repeated-measures ANOVA (with time as a within-subject variable and diet and genetic group as between-subject variables) with Bonferroni adjustment when applicable. Pearson's correlation tests were used to evaluate the association of the gut microbiota with body weight and body fat as well as blood biochemistry and energy intake. Data were analysed using SPSS Statistics 17.0 (SPSS, Inc.,
Chicago, IL, USA). The result was considered significant when $P \leq 0 \cdot 05$.

\section{Results}

Prebiotics dose-dependently increase gut weight but do not alter body fat in JCR:LA-CP rats

Body weight did not differ with prebiotic supplementation in lean or obese rats over the 10-week study (Fig. 1(a)). Adjusting for the greater gut weight in the F groups (Table 3) did not alter these results. A $25 \%$ reduction in percentage of body fat in lean rats fed the highest dose of fibre did not reach significance $(P>0 \cdot 1$, Fig. 1(b)). No other parameters measured using dual-energy X-ray absorptiometry differed among groups including absolute lean and fat mass and bone mineral density (data not shown).

Small-intestinal length was $17 \%$ longer in obese $v$. lean rats $(P<0 \cdot 01$; Table 3$)$. The HF diet also increased small-intestinal length compared with the $\mathrm{C}$ and $\mathrm{F}$ diets. In lean and obese rats, the weight of the caecum and colon increased dosedependently with $\mathrm{F}$ supplementation $(P<0 \cdot 001)$. Total gut weight was increased in obese $v$. lean rats as well as dosedependently with $\mathrm{F}$ supplementation $(P<0 \cdot 01)$.
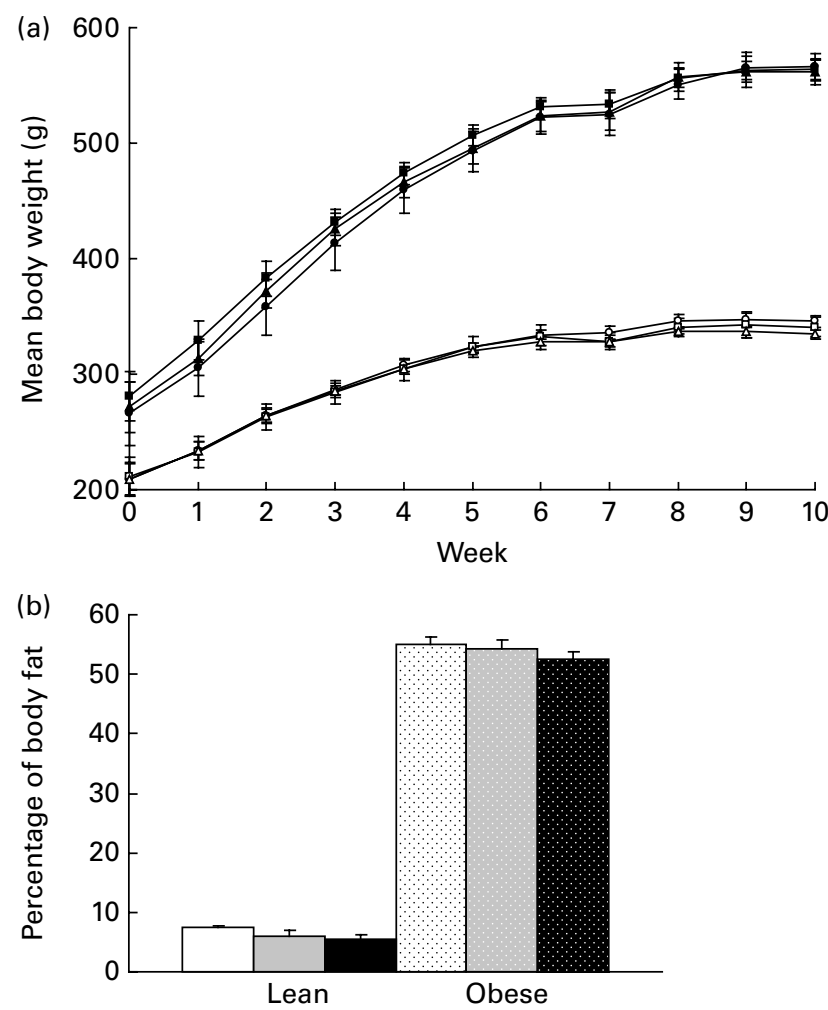

Fig. 1. (a) Weekly body weights and (b) percentage of body fat as determined by dual-energy X-ray absorptiometry for lean and obese rats on control $(0 \%)$, fibre $(10 \%)$ and high-fibre $(20 \%)$ prebiotic diets. Values are means, with their standard errors represented by vertical bars $(n 8)$. Mean values were not significantly different within genetic groups $(P>0.05$; two-way ANOVA and repeated-measures ANOVA). LC ((a) - -; (b) $\square$ ), lean

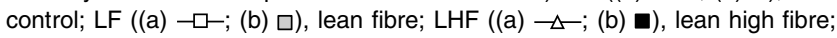
OC ((a) —-; (b) $\boxminus)$, obese control; OF ((a)-—; (b) $\square)$, obese fibre; OHF ((a) $\neg$; (b) $\mathbf{a})$, obese high fibre. 
Prebiotic enhances glucagon-like peptide-1 and blunts ghrelin response to a meal

There was a significant effect of the prebiotic on GLP-1 during the meal tolerance test with a higher tAUC in the HF group compared with the $\mathrm{C}$ group $(P<0 \cdot 01)$. tAUC for GLP-1 was increased in lean $20 \%$ fibre (LHF) compared with lean $0 \%$ fibre (LC) and in obese $20 \%$ fibre (OHF) compared with obese $0 \%$ fibre (OC; $P=0 \cdot 01$, Fig. 2(b)). There was a significant diet effect for ghrelin with tAUC in the LHF $(P=0.007)$ and lean $10 \%$ fibre (LF; $P=0.04$ ) groups lower than the LC group. Ghrelin concentrations at fasting, 15 and $30 \mathrm{~min}$ were lower in obese $v$. lean rats $(P<0 \cdot 001$; Fig. 2(a)) and showed minimal response to the meal.

\section{Proglucagon and peptide YY mRNA levels are increased} with prebiotic intake while ghrelin O-acyltransferase $m R N A$ is decreased in obese rats at high intake

In lean rats, prebiotics increased proglucagon and PYY mRNA levels in the caecum with a 2-fold increase in the LF group and a 3-fold increase in the LHF group. PYY was up-regulated in the middle segment of the small intestine in the LHF group (Fig. 3). Ghrelin was down-regulated $40 \%$ in the ileum of both LF and LHF groups compared with the LC group.

In obese rats, proglucagon and PYY mRNA levels were increased in the caecum with the obese $10 \%$ fibre (OF) and OHF diets. There was a dose-response in colonic proglucagon mRNA with a $1 \cdot 7$-fold increase in the OF group and a $2 \cdot 5$-fold increase in the OHF group. A similar trend was observed with PYY expression. In the proximal small intestine, OHF increased proglucagon and PYY expression by 1.5 -fold and 9-fold, respectively, compared with the other diets. There was a approximately 4-fold increase in PYY mRNA levels in the middle small intestine and an approximately 2 -fold increase in the distal small intestine with OHF supplementation (Fig. 3). There was a $50 \%$ decrease in ghrelin mRNA in the proximal small intestine in the OHF group $(P<0 \cdot 05)$. Finally, there were 45 and $32 \%$ decreases in ghrelin mRNA levels with OF and OHF supplementation, respectively, in the middle segment of the small intestine (Fig. 3).

In obese rats, GOAT mRNA expression was significantly decreased $(P=0.05)$ with OHF supplementation compared with OC and OF supplementation (Fig. 4). When all obese rats were compared with all lean rats, there was a significant 2.0-fold higher expression of GOAT mRNA in the stomach in obese $v$. lean rats $(P=0.03)$.

\section{Energy intake but not energy expenditure or gastric emptying is altered with prebiotic}

Food intake was greater in obese $v$. lean rats and increased with prebiotic in the HF group compared with the $\mathrm{C}$ group $(P=0 \cdot 02)$. Energy intake (grams of food consumption multiplied by energy density of the diet) was reduced in the $\mathrm{F}$ and $\mathrm{HF}$ groups compared with the $\mathrm{C}$ group. Prebiotic fibre resulted in a $6 \%$ decrease in energy intake in the LF and OF groups, an $11 \%$ decrease in the LHF group and an $8 \%$ decrease in the OHF group compared with the OC group $(P<0.05$; Fig. 5). The mean daily food intake for lean rats in the $\mathrm{C}, \mathrm{F}$ and $\mathrm{HF}$ groups was $15 \cdot 1$ (SD 0.6), $15 \cdot 2$ (SD 0.7) and 15.7 (SD 1.1) $\mathrm{g} / \mathrm{d}$ compared with obese rats in the $\mathrm{C}, \mathrm{F}$ and HF groups at 24.8 (SD 1.8), 25.0 (SD 1.9) and 26.7 (SD 2.0) g/d, respectively. Conversely, the mean energy intake for lean rats in the C, F and HF groups was 239.3 (SD 9.2), 225.1 (SD 10.3) and $217 \cdot 1$ (SD 14.9) kJ/d compared with obese rats in the C, F and HF groups at 394.9 (SD 28.5), $370 \cdot 7$ (SD 28.49) and 369.0 (SD 27.9$) \mathrm{kJ} / \mathrm{d}$, respectively. For both food intake and energy intake, there was a significant effect of genetic group and diet.

No difference in the relative amount of carbohydrate and fat energy expenditure was detected among the groups during the $23 \mathrm{~h}$ test in lean or obese rats. RER values for the LC, LF, and LHF groups were 0.94 (SD 0.01), 0.93 (SD 0.01) and 0.94 (SD 0.01), respectively, while those for the OC, OF, and OHF

Table 3. Physical characteristics and daily energy intake

(Mean values with their standard errors, $n 8$ )

\begin{tabular}{|c|c|c|c|c|c|c|c|c|c|c|c|c|}
\hline & \multicolumn{2}{|c|}{ LC } & \multicolumn{2}{|c|}{ LF } & \multicolumn{2}{|c|}{ LHF } & \multicolumn{2}{|c|}{$O C$} & \multicolumn{2}{|c|}{ OF } & \multicolumn{2}{|c|}{$\mathrm{OHF}$} \\
\hline & Mean & SEM & Mean & SEM & Mean & SEM & Mean & SEM & Mean & SEM & Mean & SEM \\
\hline Body weight (g) & $345 \cdot 6$ & $14 \cdot 2$ & $340 \cdot 6$ & $23 \cdot 8$ & 334.4 & $10 \cdot 4$ & $566 \cdot 1$ & $28 \cdot 9$ & 563.5 & $26 \cdot 0$ & 561.5 & $28 \cdot 8$ \\
\hline Energy intake $(\mathrm{kJ} / \mathrm{d})$ & 233.9 & 2.9 & $220 \cdot 2$ & 3.0 & $209 \cdot 4^{*}$ & 3.8 & $385 \cdot 7$ & 8.7 & $362 \cdot 4^{*}$ & 7.9 & $354.8^{*}$ & 8.9 \\
\hline Stomach weight $(\mathrm{g})$ & 1.88 & 0.36 & 2.09 & 0.57 & 1.85 & 0.30 & $2 \cdot 43 \ddagger$ & 0.39 & $2 \cdot 19$ & 0.22 & $2 \cdot 26 \ddagger$ & 0.21 \\
\hline SI length $(\mathrm{cm})$ & $104 \cdot 7$ & 3.6 & $104 \cdot 3$ & 3.5 & $108 \cdot 9$ & 3.4 & $123 \cdot 1 \ddagger$ & $6 \cdot 1$ & $120 \cdot 9 \ddagger$ & $5 \cdot 1$ & $129 \cdot 7^{*} \dagger \ddagger$ & 1.6 \\
\hline SI weight $(\mathrm{g})$ & $4 \cdot 81$ & 0.54 & 4.62 & 0.42 & 4.85 & 0.71 & $6.74 \ddagger$ & 1.03 & $7 \cdot 04 \ddagger$ & 0.60 & $8.02^{*} \dagger \ddagger$ & 0.35 \\
\hline Caecal weight $(\mathrm{g}) \S$ & $2 \cdot 71$ & 1.07 & $6 \cdot 87^{*}$ & 1.39 & $9 \cdot 35^{\star} \dagger$ & 1.36 & 2.08 & 0.58 & $5 \cdot 04^{*} \ddagger$ & $1 \cdot 14$ & $8 \cdot 44^{*} \dagger$ & 2.35 \\
\hline Colon length $(\mathrm{cm})$ & $12 \cdot 4$ & $2 \cdot 1$ & $16 \cdot 3^{*}$ & $2 \cdot 7$ & $16 \cdot 3^{*}$ & $2 \cdot 6$ & $16 \cdot 9 \ddagger$ & $3 \cdot 0$ & $17 \cdot 8$ & $2 \cdot 6$ & $20 \cdot 9^{*} \ddagger$ & $2 \cdot 3$ \\
\hline Colon weight (g) & 0.95 & 0.13 & $1 \cdot 16$ & $0 \cdot 17$ & $1.78^{*} \dagger$ & 0.72 & 1.27 & 0.14 & 1.42 & 0.21 & $2 \cdot 06^{*} \dagger$ & 0.51 \\
\hline TG weight $(g) \|$ & $10 \cdot 4$ & $1 \cdot 0$ & $14 \cdot 7^{\star}$ & 1.7 & $17 \cdot 8^{\star} \dagger$ & $1.7 \dagger$ & $12 \cdot 5 \ddagger$ & $1 \cdot 6$ & $15 \cdot 7^{*}$ & $1 \cdot 7$ & $20 \cdot 8^{\star} \dagger \ddagger$ & $2 \cdot 4$ \\
\hline GB weight (g)ף & $335 \cdot 2$ & 14.4 & $325 \cdot 8$ & $23 \cdot 3$ & $316 \cdot 6$ & $10 \cdot 7$ & $554 \cdot 7 \ddagger$ & $26 \cdot 5$ & $547.5 \ddagger$ & $23 \cdot 0$ & $540 \cdot 8 \ddagger$ & 27.5 \\
\hline
\end{tabular}

LC, lean control; LF, lean fibre; LHF, lean high fibre; OC, obese control; OF, obese fibre; OHF, obese high fibre; SI, small intestine; TG, total gut; GB, gutless body weight.

* Mean values were significantly different from the control diet within the respective lean and obese groups $(P<0.05$; two-way ANOVA).

$\dagger$ Mean values were significantly different between $10 \%$ and $20 \%$ fibre within the lean and obese groups $(P<0.05$; two-way ANOVA).

$\ddagger$ Mean values were significantly different between lean and obese within the respective diet groups $(P<0.05$; two-way ANOVA).

$\S$ Caecal weight refers to the caecal tissue and its contents.

II TG weight was calculated by adding the weight of the stomach, SI, caecum and colon.

I Body weight without the gut was determined by subtracting total gut weight from body weight. 
(a)

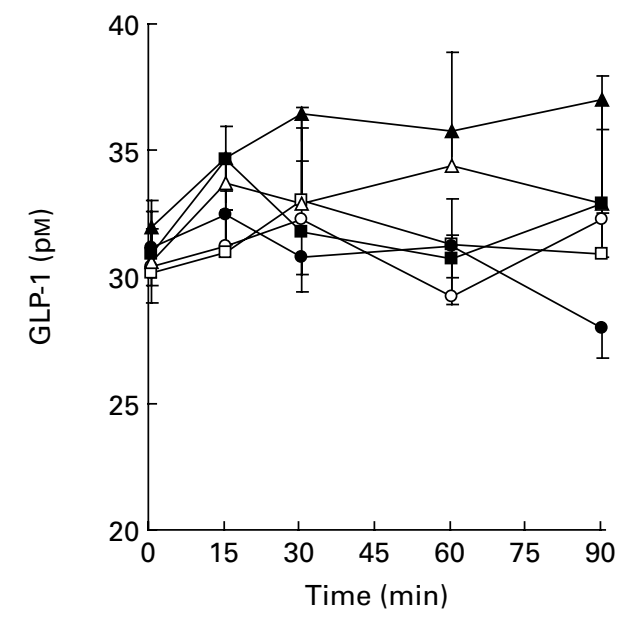

(b)

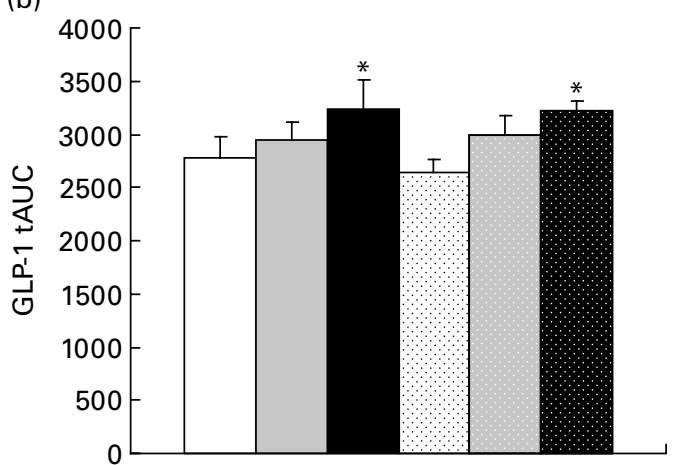

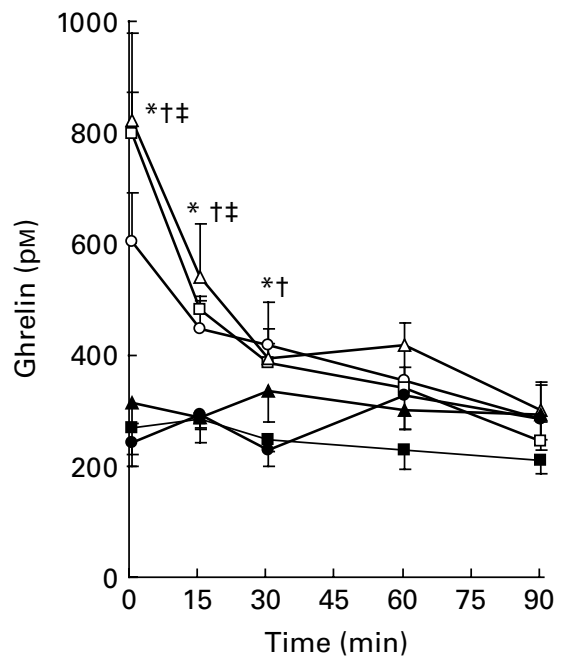

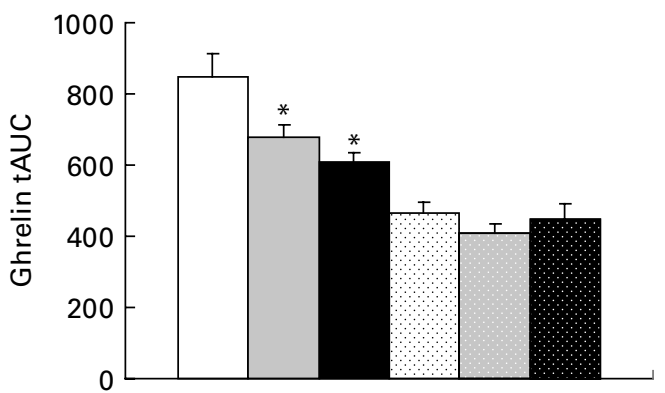

Fig. 2. Glucagon-like peptide-1 (GLP-1; active) and des-acyl ghrelin in lean and obese rats fed increasing doses of prebiotic. Values are means, with their standard errors represented by vertical bars $(n 8)$. (a) Serial values during the 90 min meal tolerance test. * Mean values were significantly different between the lean and obese groups from those of control diets $(P \leq 0.05$; two-way ANOVA and repeated-measures ANOVA). $†$ Mean values were significantly different between the lean and obese groups from those of $10 \%$ fibre diets $(P \leq 0.05$; two-way ANOVA and repeated-measures ANOVA). $\ddagger$ Mean values were significantly different between the lean and obese groups from those of $20 \%$ fibre diets $(P \leq 0.05$; two-way ANOVA and repeated-measures ANOVA). (b) Total area under the curve (tAUC). ${ }^{*}$ Mean values were significantly different from those of the control within the lean or obese groups $(P \leq 0.05$; two-way ANOVA and

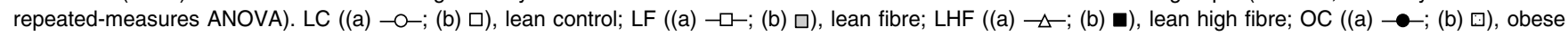

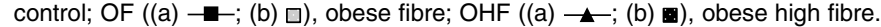

groups were 0.95 (SD 0.01), 0.94 (SD 0.01) and 0.95 (SD 0.01), respectively. Gastric emptying was accelerated in obese $v$. lean rats at individual time points during the test as well as tAUC $(P<0 \cdot 001 ;$ Fig. 6). Prebiotic did not alter acetaminophen appearance in plasma at any point over the 90 min test nor was tAUC changed.

\section{Glucagon but not glucose or insulin is decreased by prebiotic}

Plasma glucose was increased in obese $v$. lean rats, suggesting impaired glucoregulation (Fig. 7(a)). Although glucose iAUC was $14 \%$ lower in the LF group than in the LC group and $25 \%$ lower in the LHF group than in the LC group, this difference was not significant (Fig. 7(b)). Insulin was significantly higher in obese $v$. lean rats $(P<0.05)$. Within the obese groups, insulin was increased in the OF group compared with the OC group at 0 and $30 \mathrm{~min}$ but no differences were seen in iAUC. Glucagon tAUC was decreased in the $\mathrm{F} v$. HF group ( $P=0.03)$; however, no differences were observed when the results were stratified by genetic group. No differences were seen in amylin.

\section{Composition of the gut microbiota changes with prebiotic in lean and obese JCR:LA-CP rats}

There was a significant effect of genetic group $(P<0.01)$ for all bacterial populations examined except for Clostridium coccoides and Enterobacteriaceae (Table 4). Total bacteria and Bacteroides were significantly lower in obese $v$. lean rats. There was a significant effect of diet for all populations examined except total bacteria and C. coccoides. There was a significant interaction between diet and genetic group for Bifidobacterium spp., Enterobacteriaceae, total bacteria, C. coccoides, Clostrium leptum and Lactobacillus spp. $(P<0.05)$. Bifidobacterium spp. were dose-dependently increased with prebiotic in both lean and obese rats $(P<0.05)$. Lactobacillus spp. were significantly increased in the OHF group $v$. OC 

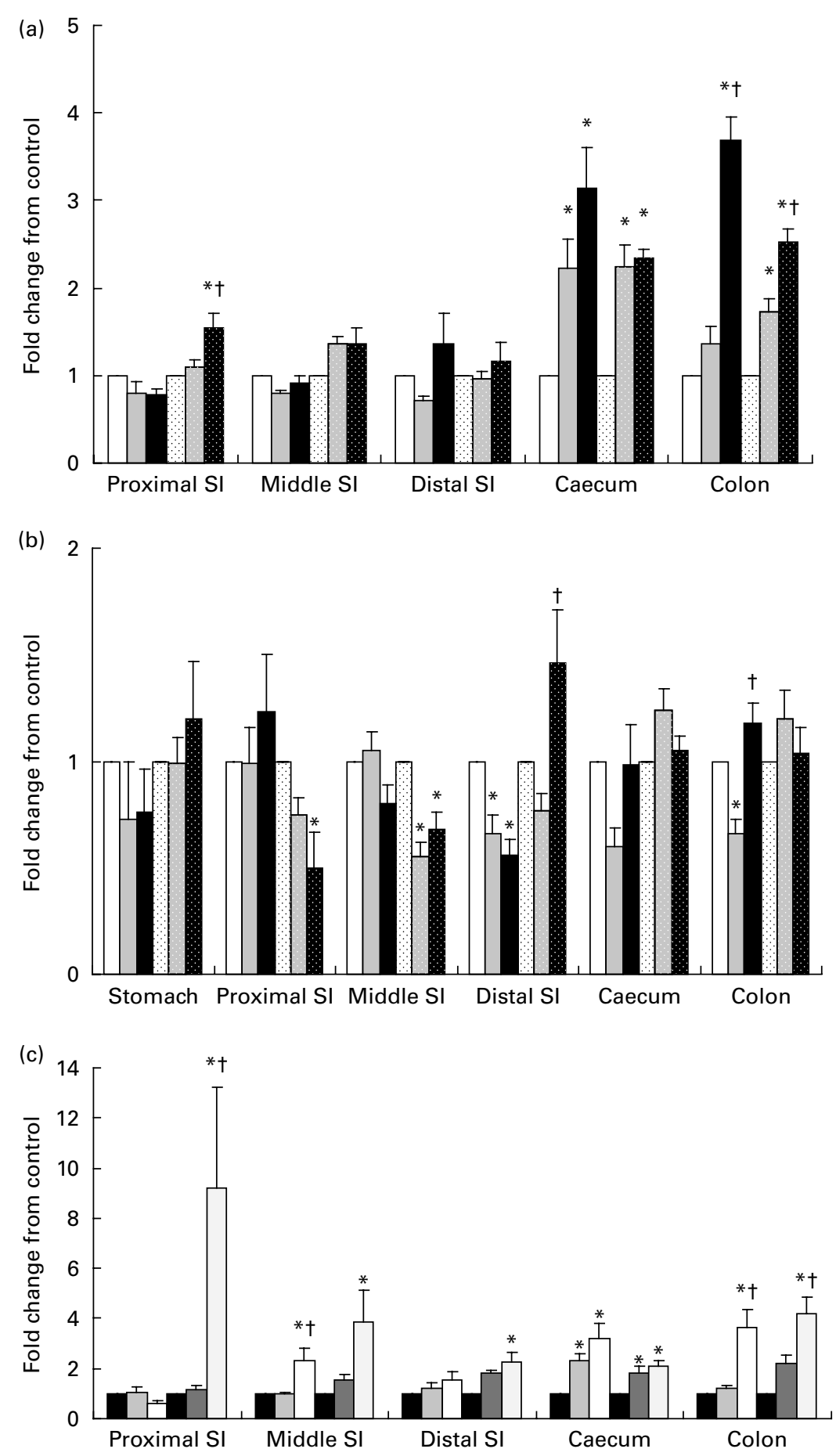

Fig. 3. (a) Proglucagon, (b) ghrelin and (c) peptide YY (PYY) mRNA levels in lean and obese rats exposed to a control, fibre or high-fibre diet. Values are means, with their standard errors represented by vertical bars $(n 8)$. * Mean values were significantly different from the control diet $(P \leq 0 \cdot 05$; one-way ANOVA). $†$ Mean values were significantly different between the fibre and high-fibre diets within genetic groups $(P \leq 0.05$; one-way ANOVA). LC ( $\square$ ), lean control; LF ( $\square$ ), lean fibre; LHF $(\square)$, lean high fibre; OC $(\square)$, obese control; OF $(\square)$, obese fibre; OHF $(\square)$, obese high fibre; SI, small intestine.

and OF groups. The C. coccoides group was reduced in the $\mathrm{OF}$ group compared with the OHF group but not compared with the $\mathrm{C}$ group $(P<0 \cdot 05)$. The Bacteroides group was increased in the HF groups in both lean and obese rats compared with the $\mathrm{C}$ groups, whereas Clostridium leptum increased in the OHF group compared with the OC and OF groups but decreased in the LHF group compared with the LC group. There were no differences in Enterobacteriaceae in lean rats but a significant increase in the OHF group compared with the OC and OF groups $(P<0 \cdot 05)$. Independent of genetic group, prebiotic fibre dose-dependently increased the Bacteroidetes groups measured in the 0, 10 and $20 \%$ prebiotic 


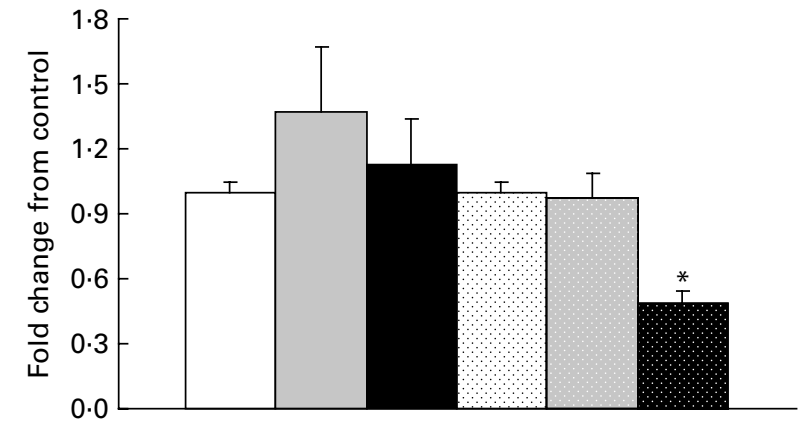

Fig. 4. Ghrelin $O$-acyltransferase mRNA levels in lean and obese rats exposed to a control, fibre or high-fibre diet. Values are means, with their standard errors represented by vertical bars $(n 8)$. * Mean values were significantly different from the control diet within the obese groups $(P<0.05)$. LC $(\square)$, lean control; LF $(\square)$, lean fibre; LHF $(\square)$, lean high fibre; OC $(\square)$, obese control; OF ( $\square)$, obese fibre; OHF ( $\mathbf{0})$, obese high fibre.

groups. Likewise, diet and genetic group affected the Firmicutes groups quantified here with an increase in obese $v$. lean rats. Independent of genetic group, prebiotic fibre decreased the Firmicutes groups measured with the 10 and $20 \%$ dose showing equal effects.

\section{Gut microbiota correlate with biomarkers of obesity}

Bacteriodes and total bacteria were negatively correlated with percentage of body fat and body weight, whereas levels of Lactobacillus spp. were positively correlated with body weight and fat as well as with total energy intake and glucose iAUC $(P<0 \cdot 05)$. Enterobacteriaceae increased in conjunction with glucose iAUC and GLP-1 tAUC. Bacteroides and total bacteria were positively correlated with ghrelin tAUC yet negatively correlated with fasting insulin, insulin iAUC and energy intake.

\section{Discussion}

Diets enriched with prebiotic fibre at a dose of $10 \%$ have previously been shown to reduce weight gain and fat mass development in rats ${ }^{(3)}$. The present study was undertaken to

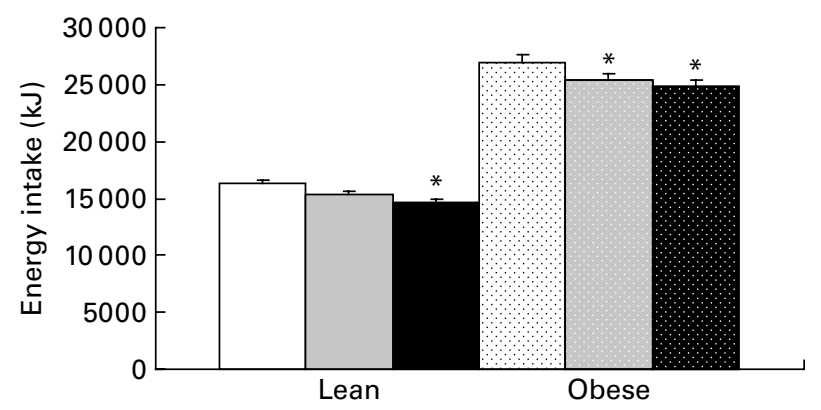

Fig. 5. Cumulative energy intake for lean and obese rats on the control, fibre and high-fibre prebiotic diets over 10 weeks. Values are means, with their standard errors represented by vertical bars $(n 8)$. * Mean values were significantly different from the control within the respective lean and obese groups $(P \leq 0.05$; two-way ANOVA). LC ( $\square$ ), lean control; LF ( $\square)$, lean fibre; LHF ( $\square$ ),

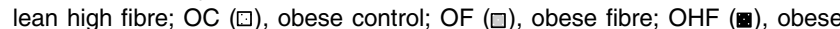
high fibre.
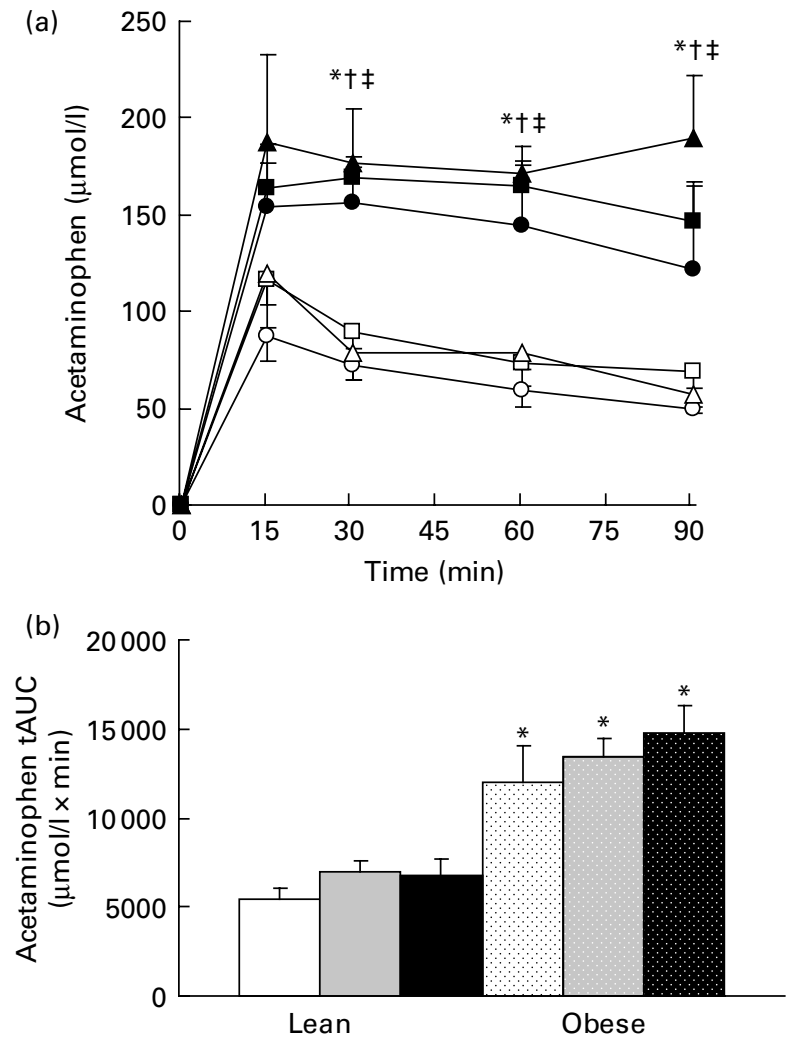

Fig. 6. Acetaminophen levels during a gastric emptying test. Values are means, with their standard errors represented by vertical bars $(n 6)$. (a) Serial values during the $90 \mathrm{~min}$ test. * Mean values were significantly different between the lean and obese groups from those of the control diets $(P \leq 0.05$; two-way ANOVA and repeated-measures ANOVA). † Mean values were significantly different between the lean and obese groups from those of the $10 \%$ fibre diets $(P \leq 0.05$; two-way ANOVA and repeated-measures ANOVA). $\ddagger$ Mean values were significantly different between the lean and obese groups from those of the $20 \%$ fibre diets $(P \leq 0.05$; two-way ANOVA and repeated-measures ANOVA). (b) Total area under the curve (tAUC). * Mean values were significantly different between obese and lean within a diet group ( $P \leq 0.05$; two-way ANOVA and repeated-measures ANOVA). LC

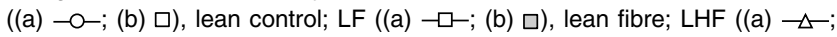
(b) घ), lean high fibre; OC ((a) - - ; (b) $\square)$, obese control; OF ((a) - (b) $\square)$, obese fibre; $\operatorname{OHF}((\mathrm{a}) \multimap-$; (b) $\mathbf{0})$, obese high fibre.

determine whether the effects of prebiotics are regulated dose-dependently and to specifically determine whether gut microbiota beyond the traditionally measured Bifidobacterium and Lactobacillus spp. are modulated by prebiotics in a monogenic model of obesity. Our findings suggest that prebiotics chiefly affect energy balance by reducing energy intake. Both satiety hormone levels and numerous gut bacterial groups not previously described in supplemented obese models are modulated by prebiotics in a dose-dependent manner.

Ingestion of prebiotics alters the physical characteristics of the gut, most notable of which is an increase in gut weight and length, particularly the caecum and colon. This proliferative effect of fibre has important implications with respect to satiety hormone secretion, as these are the primary tissues involved in GLP-1 and PYY production. Augmented gut proliferation is supported in the present study by elevated expression of proglucagon, the precursor of GLP-2, a gut 

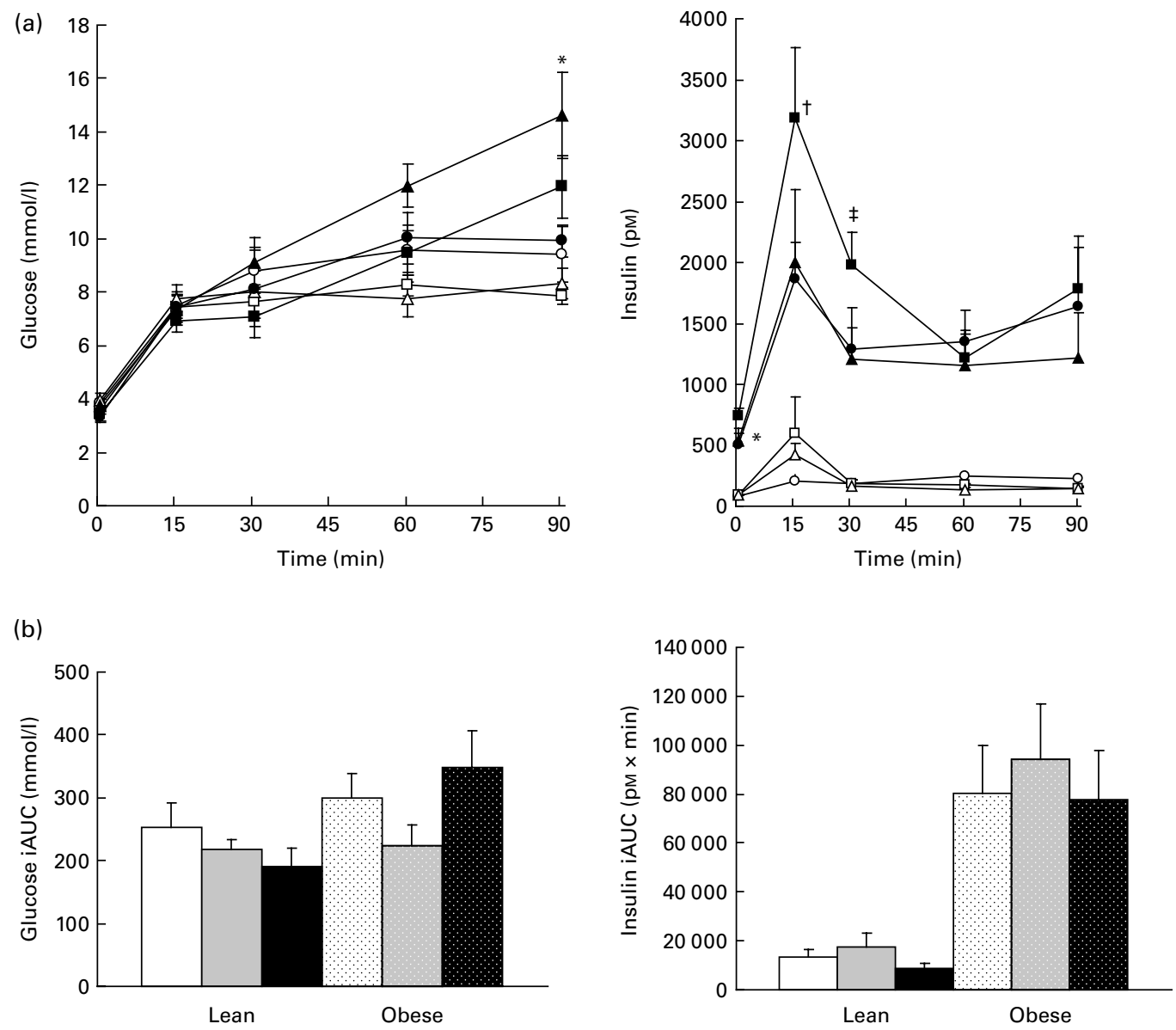

Fig. 7. Whole blood glucose values and plasma insulin. Values are means, with their standard errors represented by vertical bars $(n 8)$. (a) Serial values during the $90 \mathrm{~min}$ meal tolerance test. ${ }^{*}$ Mean values were significantly different between the $\mathrm{OC}$ and OF diets $(P \leq 0.05$; two-way ANOVA and repeated-measures ANOVA). $†$ Mean values were significantly different between the OC and OHF diets $(P \leq 0.05$; two-way ANOVA and repeated-measures ANOVA). $\ddagger$ Mean values were significantly different between the OF and OHF diets $(P \leq 0.05$; two-way ANOVA and repeated-measures ANOVA). (b) Incremental area under the curve

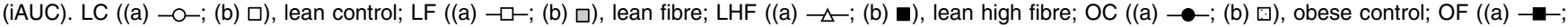
(b) $\square)$, obese fibre; OHF ((a) $\_$; (b) 1$)$, obese high fibre.

trophic hormone ${ }^{(7)}$. While the increase in gut weight that we observed with prebiotics has previously been reported ${ }^{(12)}$, the lack of reduction in body weight and fat mass is contrary to many but not all reports with oligofructose supplementation $^{(10,34)}$

It is well established that one of the metabolic by-products of prebiotic fibre metabolism by gut microbiota is SCFA. Although we did not measure SCFA in the present study, others have reported that prebiotic fibres increase the levels of SCFA and link this to increased expression of proglucagon $^{(12,13,35,36)}$. Indeed, we report increases in both proglucagon and plasma GLP-1. There are several probable explanations for the contradictory results between the significant increase in GLP-1 and lack of weight loss. Although the increase in proglucagon expression and GLP-1 secretion is statistically significant, it is possible that it is insufficient to induce a physiologically meaningful change in body weight in this specific model of monogenic obesity. We have previously observed a similar increase in GLP-1 and decrease in energy intake without concomitant weight loss in the JCR:LA-cp rat fed a combination of a high-protein/HF $\operatorname{diet}^{(37)}$. Additionally, although it has been well established that exogenous GLP-1 regulates satiety and promotes weight loss, GLP-1R ${ }^{-/-}$mice have normal food intake and body weight consuming either a normal or high-fat diet ${ }^{(38,39)}$, suggesting that other factors may override the satiogenic effects of GLP-1 secretion.

Plasma des-acyl ghrelin and ghrelin mRNA in the distal small intestine were decreased with prebiotic fibre in lean rats. In addition to the diet-induced effects, there were also notable differences in ghrelin secretion between lean and obese rats, with obese rats showing attenuated ghrelin levels both at fasting and in response to a meal. Other studies have supported an attenuated ghrelin response to food stimulus in human subjects with obesity ${ }^{(40,41)}$. While gastric ghrelin mRNA did not change with prebiotics in lean or obese rats, GOAT mRNA in the stomach was significantly reduced by the $20 \%$ fibre dose in obese rats. Obese rats also showed a 2.0-fold higher expression of GOAT mRNA than lean rats. GOAT, which acylates ghrelin and gives it potent orexigenic and growth hormone-stimulating actions ${ }^{(14,15)}$, has not been described by others in the JCR:LA-cp rat but Kirchner 
Table 4. Faecal microbiota composition of lean and obese JCR:LA-cp rats fed a 0,10 or $20 \%$ prebiotic fibre diet for 10 weeks§

(Mean values with their standard errors, $n 6-8$ )

\begin{tabular}{|c|c|c|c|c|c|c|c|c|c|c|c|c|}
\hline \multirow[b]{3}{*}{ Population } & \multicolumn{4}{|c|}{$0 \%$} & \multicolumn{4}{|c|}{$10 \%$} & \multicolumn{4}{|c|}{$20 \%$} \\
\hline & \multicolumn{2}{|c|}{ Lean } & \multicolumn{2}{|c|}{ Obese } & \multicolumn{2}{|c|}{ Lean } & \multicolumn{2}{|c|}{ Obese } & \multicolumn{2}{|c|}{ Lean } & \multicolumn{2}{|c|}{ Obese } \\
\hline & Mean & SEM & Mean & SEM & Mean & SEM & Mean & SEM & Mean & SEM & Mean & SEM \\
\hline Total bacteria & 713.4 & $106 \cdot 0$ & $360 \cdot 6 \ddagger$ & 79.4 & $745 \cdot 7$ & $56 \cdot 7$ & $390 \cdot 2 \ddagger$ & $59 \cdot 1$ & $660 \cdot 6$ & 64.9 & $719 \cdot 0^{*} \dagger$ & 84.0 \\
\hline Bacteroides/Prevotella & $168 \cdot 4$ & $42 \cdot 4$ & $33.0 \ddagger$ & 9.4 & $266 \cdot 1$ & $26 \cdot 0$ & $120.0 \ddagger$ & $35 \cdot 7$ & $348 \cdot 2^{*}$ & 43.6 & $225 \cdot 3^{\star} \ddagger$ & 69.7 \\
\hline Clostridium coccoides (group XIV) & 251.9 & $20 \cdot 2$ & 223.6 & $39 \cdot 2$ & $210 \cdot 6$ & 41.9 & 129.0 & $129 \cdot 0$ & $102 \cdot 2^{*}$ & $22 \cdot 0$ & $343.4 \dagger \ddagger$ & $76 \cdot 0$ \\
\hline Clostridium leptum (subgroup IV) & $15 \cdot 1$ & 3.4 & $0.8 \ddagger$ & 0.2 & $7 \cdot 9$ & 1.6 & $8 \cdot 6$ & 1.5 & $4 \cdot 1^{*}$ & $1 \cdot 2$ & $35 \cdot 8^{*}+\ddagger$ & 8.9 \\
\hline Lactobacillus & $14 \cdot 0$ & 2.5 & $19 \cdot 4$ & $6 \cdot 3$ & $14 \cdot 1$ & 3.6 & $22 \cdot 2$ & 5.4 & $15 \cdot 5$ & $6 \cdot 0$ & $70 \cdot 6^{*} \dagger \ddagger$ & 14.4 \\
\hline Bifidobacterium & 0.8 & 0.4 & 0.8 & 0.2 & $5 \cdot 1$ & 1.5 & $8 \cdot 6$ & 1.5 & $14 \cdot 5^{\star}$ & $5 \cdot 5$ & $35 \cdot 8^{\star}+\ddagger$ & 8.9 \\
\hline Enterobacteriaceae & 3.9 & 0.6 & $1.4 \ddagger$ & 0.9 & $2 \cdot 6$ & 0.7 & 1.4 & 0.3 & $2 \cdot 8$ & 1.1 & $6 \cdot 5^{\star} \dagger \ddagger$ & 1.7 \\
\hline
\end{tabular}

* Mean values were significantly different from the control diet within the respective lean and obese groups $(P<0.05$; two-way ANOVA).

† Mean values were significantly different between the $10 \%$ and $20 \%$ fibre diets within the lean and obese groups $(P<0.05$; two-way ANOVA).

$\ddagger$ Mean values were significantly different between lean and obese within the respective diet groups $(P<0.05$; two-way ANOVA).

$\S$ Data are expressed as pg bacterial DNA/ng total genomic DNA.

et $a{ }^{(42)}$ and Gahete et $^{\left(4 l^{(43)}\right.}$ did demonstrate an approximate $1 \cdot 7$-fold increase in GOAT mRNA in ob/ob mice compared with age-matched wild-type mice which did not reach statistical significance. While a comprehensive understanding of the roles and regulation of GOAT is not yet available, Kirchner et al. ${ }^{(42)}$ recently showed that production of active ghrelin in vivo is dependent on GOAT and diet composition, specifically medium-chain TAG availability. Some have suggested that blocking GOAT could be a strategy to prevent dietinduced obesity ${ }^{(44)}$.

Food intake was either unaffected or increased with prebiotic fibres; however, due to the lower energy value of the fibre diets, overall energy intake was reduced ${ }^{(17)}$. This supports the theory of energy dilution as a mechanism of action of prebiotic fibres. We cannot rule out that the lower energy value of the diets and altered food intake did not also indirectly influence overall energy balance via changes in gut microbiota. Conversely, energy expenditure was not altered with prebiotic supplementation, indicating that changes in metabolic rate do not occur with increased prebiotic intake in the JCR:LA-cp rat. Gastric emptying was not affected with prebiotic consumption but was increased in obese $v$. lean rats. Although controversial ${ }^{(45)}$, increased rates of gastric emptying in obesity have been previously reported $^{(46)}$ and may be linked to reduced satiety in obesity. Of special note with regard to satiety is that all of our diets were formulated to provide an equivalent amount of energy from fat and protein, thereby increasing the likelihood that changes in satiety were due to the addition of prebiotic fibre rather than alterations in protein or fat contribution to total energy of the diet.

In addition to disrupted gut satiety endocrine function, recent evidence suggests that analogous differences in the distal gut bacteria of obese $v$. lean mice and human subjects also play a role in obesity and contribute to the low-grade inflammatory state of obesity ${ }^{(23,47,48)}$. We confirm the decrease in Bacteriodetes and the corresponding increase from the division Firmicutes that has been described for obese mice and human subjects ${ }^{(23,47,48)}$. Furthermore, we demonstrate a significant shift in the Bacteroidetes and Firmicutes groups that is brought about with increasing doses of prebiotic fibre intake. Where our work specifically adds to the current body of knowledge is its assessment of the effects of obesity and prebiotics on other bacteria groups not traditionally measured. The impact of these strains on obesity requires further investigation; however, one study has reported that weight loss in overweight adolescents reduced Bifidobacterium spp. levels ${ }^{(49)}$, which supports our results.

Given that prebiotics alter the composition of the gut microbiota, there is significant interest in their ability to do so in a manner that promotes weight loss. Here, we report increases in Lactobacillus spp. with prebiotic supplementation. These results are promising as perinatal probiotic treatment with Lactobacillus rhamnosus has been shown to attenuate excessive weight gain in the first years of life ${ }^{(50)}$ and Lactobacillus gasseri reduced abdominal adiposity and body weight in adults with obese tendencies ${ }^{(51)}$. Our 1:1 mixture of inulin and oligofructose also increased Bacteroides, suggesting that prebiotics may be able to normalise the reduced Bacteroidetes numbers reported in obesity. While others have shown that prebiotic fibres increase gut Bifidobacterium spp. numbers ${ }^{(26)}$, the present study is the first to show that this response is dose-dependent in lean and obese JCR:LA-cp rats. The gut microbiota has been linked to body fat through a variety of mechanisms including increased energy harvesting, hepatic de novo lipogenesis, adipocyte fatty acid storage, presumably through lipoprotein lipases, and suppression of AMP-activated protein kinase-dependent fatty acid oxidation ${ }^{(20)}$. Cani et al. ${ }^{(52)}$ have shown that a high-fat diet increases intestinal permeability, which is considered a chief contributor to higher plasma lipopolysaccharide levels and consequent metabolic endotoxaemia. It has been proposed that prebiotics reduce the impact of high-fat diet-induced metabolic endotoxaemia in part by increasing the gut trophic factor GLP-2 and lowering intestinal permeability ${ }^{(26)}$. The increased proglucagon mRNA levels that we report with prebiotic would support such an increase in GLP-2 production. Furthermore, the correlation between the gut microflora and satiety hormones, energy intake and insulin levels is novel and emphasises the complexity of the system. In summary, the shift in microbial profile 
that we induced with an increasing dose of prebiotic probably contributes to overall improvements in health, particularly those aspects related to the development and maintenance of obesity.

We are aware of certain limitations of the present study. Obesity and the metabolic syndrome in humans are multifactorial and, as a result, make the identification or development of rodent models that fully represent the human condition difficult. While some monogenic models of obesity such as the Zucker $\mathrm{fa} / \mathrm{fa}$ rat or our JCR:LA-cp rat do in fact develop anomalies similar to those characterising patients with obesity and/or the metabolic syndrome ${ }^{(53)}$, it is likely that a dietinduced obesity model ${ }^{(54)}$ more closely mimics these conditions in human subjects. Interpreting our findings in light of the genetic background of the JCR:LA-cp rat is prudent. It is also difficult to isolate the independent effects of the prebiotic on the gut microbiota from the lower energy intake associated with consumption of these diets. Studies have demonstrated a significant shift in gut bacterial groups following energy restriction and weight loss ${ }^{(55,56)}$. When energy restriction was achieved with an energy-restricted diet and increased physical activity ${ }^{(55)}$ or bariatric surgery ${ }^{(57)}$, decreases in bifidobacteria were observed, which contrasts to the increases that we demonstrated in the present study. This as well as in vitro studies, showing significantly increased bifidobacteria with batch culture fermentations of prebiotics ${ }^{(58)}$, suggests that prebiotics have effects independent of energy dilution. Furthermore, it should be noted that our methods have not quantified all of the bacteria groups comprising the rodent gut microbiome ${ }^{(59)}$. Additionally, the differences between rats and humans with respect to gut bacteria must be acknowledged. These data are significant; however, as they provide justification for additional studies in diet-induced obese models and human clinical trials.

In conclusion, the present study represents a systematic dose-response analysis of the effects of prebiotic fibres in both lean and obese states. There was a significant increase in circulating GLP-1 levels and a concomitant up-regulation of proglucagon and PYY mRNA with prebiotic intake in the present study. The results are limited, however, in the use of the monogenic rat model and its specific hormonal milieu, particularly satiety hormones. Furthermore, it should be noted that our methods have not quantified all of the bacteria groups comprising the rodent gut microbiome ${ }^{(59)}$. Additionally, the differences between rats and humans with respect to gut bacteria must be acknowledged. These data are significant, however, as they provide justification for additional studies in diet-induced obese models and human clinical trials. Alterations in the gut microflora of these animals suggest that prebiotics may be able to 'shape' the bacterial communities in lean and obese animals to optimise metabolic health. The significance of the present study lies in the tremendous need for effective dietary strategies to combat the increasingly burdensome obesity epidemic. From a practical standpoint, numerous foods containing prebiotics have appeared on the market recently and additional research is required to fully understand their mechanism of action, safety and effectiveness.

\section{Acknowledgements}

The present study was supported in part by the Canadian Institutes of Health Research, the Natural Sciences and Engineering Research Council of Canada, and Mount Royal University Internal Grants. J. A. P. declares no conflict of interest. R. A. R. holds funding from the company that manufactures the prebiotics, Raftilose and Raftiline, for a project distinct from the present study. J. A. P. was involved in the study design and concept, acquisition and analysis of the data, and drafting of the manuscript. R. A. R. was involved in the study design and concept, analysis of the data, and revision of the manuscript. The authors would like to thank Kristine Lee and Kristine Cannon for their assistance with the laboratory work.

\section{References}

1. Delzenne NM (2003) Oligosaccharides: state of the art Proc Nutr Soc 62, 177-182.

2. Cani PD, Dewever C \& Delzenne NM (2004) Inulin-type fructans modulate gastrointestinal peptides involved in appetite regulation (glucagon-like peptide-1 and ghrelin) in rats. BrJ Nutr 92, 521-526.

3. Cani PD, Neyrinck AM, Maton N, et al. (2005) Oligofructose promotes satiety in rats fed a high-fat diet: involvement of glucagon-like peptide-1. Obes Res 13, 1000-1007.

4. Maurer AD, Eller LK, Hallam MC, et al. (2010) Consumption of diets high in prebiotic fiber or protein during growth influences the response to a high fat and sucrose diet in adulthood in rats. Nutr Metab (Lond) 7, 77.

5. Gevrey JC, Malapel M, Philippe J, et al. (2004) Protein hydrolysates stimulate proglucagon gene transcription in intestinal endocrine cells via two elements related to cyclic AMP response element. Diabetologia 47, 926-936.

6. Cordier-Bussat M, Bernard C, Levenez F, et al. (1998) Peptones stimulate both the secretion of the incretin hormone glucagon-like peptide 1 and the transcription of the proglucagon gene. Diabetes 47, 1038-1045.

7. Drucker DJ (2002) Biological actions and therapeutic potential of the glucagon-like peptides. Gastroenterology 122, 531-544.

8. Parnell JA \& Reimer RA (2009) Weight loss during oligofructose supplementation is associated with decreased ghrelin and increased peptide $\mathrm{YY}$ in overweight and obese adults. Am J Clin Nutr 89, 1751-1759.

9. Cani PD, Lecourt E, Dewulf EM, et al. (2009) Gut microbiota fermentation of prebiotics increases satietogenic and incretin gut peptide production with consequences for appetite sensation and glucose response after a meal. Am J Clin Nutr 90, 1236-1243.

10. Urias-Silvas JE, Cani PD, Delmee E, et al. (2008) Physiological effects of dietary fructans extracted from Agave tequilana Gto. and Dasylirion spp. Br J Nutr 99, 254-261.

11. Delmee E, Cani PD, Gual G, et al. (2006) Relation between colonic proglucagon expression and metabolic response to oligofructose in high fat diet-fed mice. Life Sci $\mathbf{7 9}$ 1007-1013.

12. Delzenne NM, Cani PD, Daubioul C, et al. (2005) Impact of inulin and oligofructose on gastrointestinal peptides. Br J Nutr 93, Suppl. 1, S157-S161.

13. Tappenden KA, Drozdowski LA, Thomson AB, et al. (1998) Short-chain fatty acid-supplemented total parenteral nutrition alters intestinal structure, glucose transporter 2 
(GLUT2) mRNA and protein, and proglucagon mRNA abundance in normal rats. Am J Clin Nutr 68, 118-125.

14. Yang J, Brown MS, Liang G, et al. (2008) Identification of the acyltransferase that octanoylates ghrelin, an appetitestimulating peptide hormone. Cell 132, 387-396.

15. Gutierrez JA, Solenberg PJ, Perkins DR, et al. (2008) Ghrelin octanoylation mediated by an orphan lipid transferase. Proc Natl Acad Sci U S A 105, 6320-6325.

16. Wettergren A, Schjoldager B, Mortensen PE, et al. (1993) Truncated GLP-1 (proglucagon 78-107-amide) inhibits gastric and pancreatic functions in man. Dig Dis Sci 38, 665-673.

17. Roberfroid MB (1999) Caloric value of inulin and oligofructose. J Nutr 129, 1436S-1437S.

18. Daubioul C, Rousseau N, Demeure R, et al. (2002) Dietary fructans, but not cellulose, decrease triglyceride accumulation in the liver of obese Zucker fa/fa rats. J Nutr $\mathbf{1 3 2}$, 967-973.

19. Savage DC (1986) Gastrointestinal microflora in mammalian nutrition. Ann Rev Nutr 6, 155-178.

20. Cani PD \& Delzenne NM (2009) Interplay between obesity and associated metabolic disorders: new insights into the gut microbiota. Curr Opin Pharmacol 9, 737-743.

21. Cani PD, Possemiers S, Van de Wiele T, et al. (2009) Changes in gut microbiota control inflammation in obese mice through a mechanism involving GLP-2-driven improvement of gut permeability. Gut 58, 1091-1103.

22. Cani PD, Bibiloni R, Knauf C, et al. (2008) Changes in gut microbiota control metabolic endotoxemia-induced inflammation in high-fat diet-induced obesity and diabetes in mice. Diabetes 57, 1470-1481.

23. Ley RE, Turnbaugh PJ, Klein S, et al. (2006) Human gut microbes associated with obesity. Nature 444, 1022-1023.

24. Duncan SH, Lobley GE, Holtrop G, et al. (2008) Human colonic microbiota associated with diet, obesity and weight loss. Int J Obes (Lond) 32, 1720-1724.

25. Zhang H, DiBaise JK, Zuccolo A, et al. (2009) Human gut microbiota in obesity and after gastric bypass. Proc Natl Acad Sci U S A 106, 2365-2370.

26. Cani PD, Neyrinck AM, Fava F, et al. (2007) Selective increases of bifidobacteria in gut microflora improve highfat-diet-induced diabetes in mice through a mechanism associated with endotoxaemia. Diabetologia 50, 2374-2383.

27. Backhed F, Ding H, Wang T, et al. (2004) The gut microbiota as an environmental factor that regulates fat storage. Proc Natl Acad Sci U S A 101, 15718-15723.

28. Koletsky S (1975) Pathologic findings and laboratory data in a new strain of obese hypertensive rats. Am J Pathol 80, 129-142

29. Parnell JA \& Reimer RA (2008) Differential secretion of satiety hormones with progression of obesity in JCR:LAcorpulent rats. Obesity (Silver Spring) 16, 736-742.

30. Hatanaka S, Kondoh M, Kawarabayashi K, et al. (1994) The measurement of gastric emptying in conscious rats by monitoring serial changes in serum acetaminophen level. J Pharmacol Toxicol Methods 31, 161-165.

31. Massimino SP, McBurney MI, Field CJ, et al. (1998) Fermentable dietary fiber increases GLP-1 secretion and improves glucose homeostasis despite increased intestinal glucose transport capacity in healthy dogs. J Nutr 128, 1786-1793.

32. Reimer RA, Maurer AD, Lau DC, et al. (2010) Long-term dietary restriction influences plasma ghrelin and GOAT mRNA level in rats. Physiol Behav 99, 605-610.

33. Livak KJ \& Schmittgen TD (2001) Analysis of relative gene expression data using real-time quantitative PCR and the 2(-Delta Delta C(T)) method. Methods 25, 402-408.
34. Boyle FG, Wrenn JM, Marsh BB, et al. (2008) Safety evaluation of oligofructose: 13 week rat study and in vitro mutagenicity. Food Chem Toxicol 46, 3132-3139.

35. Tappenden KA, Thomson AB, Wild GE, et al. (1996) Short-chain fatty acids increase proglucagon and ornithine decarboxylase messenger RNAs after intestinal resection in rats. JPEN 20, 357-362.

36. Drozdowski LA, Dixon WT, McBurney MI, et al. (2002) Short-chain fatty acids and total parenteral nutrition affect intestinal gene expression. JPEN 26, 145-150.

37. Reimer RA \& Russell JC (2008) Glucose tolerance, lipids, and GLP-1 secretion in JCR:LA-cp rats fed a high protein fiber diet. Obesity (Silver Spring) 16, 40-46.

38. Scrocchi LA, Brown TJ, MaClusky N, et al. (1996) Glucose intolerance but normal satiety in mice with a null mutation in the glucagon-like peptide 1 receptor gene. Nat Med $\mathbf{2}$, $1254-1258$.

39. Scrocchi LA \& Drucker DJ (1998) Effects of aging and a high fat diet on body weight and glucose tolerance in glucagonlike peptide-1 receptor $-/-$ mice. Endocrinology 139, 3127-3132.

40. English PJ, Ghatei MA, Malik IA, et al. (2002) Food fails to suppress ghrelin levels in obese humans. J Clin Endocrinol Metab 87, 2984-2987.

41. Zwirska-Korczala K, Konturek SJ, Sodowski M, et al. (2007) Basal and postprandial plasma levels of PYY, ghrelin, cholecystokinin, gastrin and insulin in women with moderate and morbid obesity and metabolic syndrome. J Physiol Pharmacol 58, Suppl. 1, 13-35.

42. Kirchner H, Gutierrez JA, Solenberg PJ, et al. (2009) GOAT links dietary lipids with the endocrine control of energy balance. Nat Med 15, 741-745.

43. Gahete MD, Cordoba-Chacon J, Salvatori R, et al. (2010) Metabolic regulation of ghrelin O-acyl transferase (GOAT) expression in the mouse hypothalamus, pituitary, and stomach. Mol Cell Endocrinol 317, 154-160.

44. Gonzalez CR, Vazquez MJ, Lopez M, et al. (2008) Influence of chronic undernutrition and leptin on GOAT mRNA levels in rat stomach mucosa. J Mol Endocrinol 41, 415-421.

45. Gallagher TK, Geoghegan JG, Baird AW, et al. (2007) Implications of altered gastrointestinal motility in obesity. Obes Surg 17, 1399-1407.

46. Cardoso-Junior A, Coelho LG, Savassi-Rocha PR, et al. (2007) Gastric emptying of solids and semi-solids in morbidly obese and non-obese subjects: an assessment using the 13C-octanoic acid and 13C-acetic acid breath tests. Obes Surg 17, 236-241.

47. Turnbaugh PJ, Ley RE, Mahowald MA, et al. (2006) An obesity-associated gut microbiome with increased capacity for energy harvest. Nature 444, 1027-1031.

48. Backhed F, Manchester JK, Semenkovich CF, et al. (2007) Mechanisms underlying the resistance to diet-induced obesity in germ-free mice. Proc Natl Acad Sci US A 104, 979-984.

49. Santacruz A, Marcos A, Warnberg J, et al. (2009) Interplay between weight loss and gut microbiota composition in overweight adolescents. Obesity (Silver Spring) 17, 1906-1915.

50. Luoto R, Kalliomaki M, Laitinen K, et al. (2010) The impact of perinatal probiotic intervention on the development of overweight and obesity: follow-up study from birth to 10 years. Int J Obes (Lond) 34, 1531-1537.

51. Kadooka Y, Sato M, Imaizumi K, et al. (2010) Regulation of abdominal adiposity by probiotics (Lactobacillus gasseri SBT2055) in adults with obese tendencies in a randomized controlled trial. Eur J Clin Nutr 64, 636-643. 
52. Cani PD, Amar J, Iglesias MA, et al. (2007) Metabolic endotoxemia initiates obesity and insulin resistance. Diabetes 56, 1761-1772.

53. Aleixandre de Artiñano A \& Miguel Castro M (2009) Experimental rat models to study the metabolic syndrome. $\mathrm{Br} \mathrm{J}$ Nutr 102, 1246-1253.

54. Sampey BP, Vanhoose AM, Winfield HM, et al. (2011) Cafeteria diet is a robust model of human metabolic syndrome with liver and adipose inflammation: comparison to high-fat diet. Obesity 19, 1109-1117.

55. Santacruz A, Marcos A, Warnberg J, et al. (2009) Interplay between weight loss and gut microbiota composition in overweight adolescents. Obesity 17, 1906-1915.

56. Ley RE, Turnbaugh PJ, Klein S, et al. (2006) Human gut microbes associated with obesity. Nature 444, 1022-1023.

57. Furet J-P, Kong L-C, Tap J, et al. (2010) Differential adaptation of human gut microbiota to bariatric surgery-induced weight loss. Diabetes 59, 3049-3057.

58. Beards E, Tuohy K \& Gibson G (2010) Bacterial, SCFA and gas profiles of a range of food ingredients following in vitro fermentation by human colonic microbiota. Anaerobe 16, 420-425.

59. Fleissner CK, Huebel N, Abd El-Bary MM, et al. (2010) Absence of intestinal microbiota does not protect mice from diet-induced obesity. Br J Nutr 104, 919-929.

60. Amann RI, Binder BJ, Olson RJ, et al. (1990) Combination of 16S rRNA-targeted oligonucleotide probes with flow cytometry for analyzing mixed microbial populations. Appl Environ Microbiol 56, 1919-1925.
61. Liu WT, Mirzabekov AD \& Stahl DA (2001) Optimization of an oligonucleotide microchip for microbial identification studies: a non-equilibrium dissociation approach. Environ Microbiol 3, 619-629.

62. Matsuki T, Watanabe K, Fujimoto J, et al. (2004) Use of $16 \mathrm{~S}$ rRNA gene-targeted group-specific primers for real-time PCR analysis of predominant bacteria in human feces. Appl Environ Microbiol 70, 7220-7228.

63. Franks AH, Harmsen HJ, Raangs GC, et al. (1998) Variations of bacterial populations in human feces measured by fluorescent in situ hybridization with group-specific $16 \mathrm{~S}$ rRNA-targeted oligonucleotide probes. Appl Environ Microbiol 64, 3336-3345.

64. Delroisse JM, Boulvin AL, Parmentier I, et al. (2008) Quantification of Bifidobacterium spp. and Lactobacillus spp. in rat fecal samples by real-time PCR. Microbiol Res 163, 663-670.

65. Bernhard AE \& Field KG (2000) Identification of nonpoint sources of fecal pollution in coastal waters by using host-specific $16 \mathrm{~S}$ ribosomal DNA genetic markers from fecal anaerobes. Appl Environ Microbiol 66, 1587-1594.

66. Nadkarni MA, Martin FE, Jacques NA, et al. (2002) Determination of bacterial load by real-time PCR using a broadrange (universal) probe and primers set. Microbiology 148 , 257-266

67. Bartosch S, Fite A, Macfarlane GT, et al. (2004) Characterization of bacterial communities in feces from healthy elderly volunteers and hospitalized elderly patients by using realtime PCR and effects of antibiotic treatment on the fecal microbiota. Appl Environ Microbiol 70, 3575-3581. 